\title{
Por uma história da indústria fonográfica no Brasil 1900-2010:
}

\author{
uma contribuição desde a Comunicação Social
}

\author{
EDUARDO VICENTE* \\ LEONARDO DE MARCHI**
}

\begin{abstract}
RESUMO: O objetivo do presente artigo é apresentar um relato condensado da história da indústria fonográfica no Brasil, desde os primeiros anos do século XX até os dias atuais (1900-2010). Baseando-se numa pesquisa bibliográfica, que compreendeu livros publicados, teses de doutorado e as atuais pesquisas dos autores, este trabalho pretende oferecer uma visão geral da dinâmica da indústria de registros sonoros, articulando aspectos tecnológicos, econômicos e socioculturais que influenciaram o desenvolvimento dessa indústria cultural no país. Dessa forma, pretende-se lançar luz sobre relações entre esse negócio de comunicação e cultura e a música popular brasileira, auxiliando futuras pesquisas relacionadas ao tema.

PALAVRAS-CHAVE: indústria fonográfica; música popular brasileira; história social da mídia.

\section{Outline of a History of the Record Industry in Brazil: a Contribution From the Media Studies.}

\begin{abstract}
This paper presents an account of the history of the record industry in Brazil since its early years on the twentieth century to the present day (1900-2010). Based on a literature review, which comprised published books, PhD theses as well as the current research of the authors, this work provides an overview of sound recordings industry dynamics, articulating technological, economic and socio-cultural aspects that influenced the development of cultural industry in the country. Thus, the authors intend to shed light on relations between this business of communication and culture and the Brazilian popular music, hoping to assist future research related to the theme.
\end{abstract}

KEYWORDS: record industry; Brazilian popular music; media social history.

\footnotetext{
* Eduardo Vicente é Doutor em Comunicação pela USP e pós-doutor pela Birmingham School of Media da Birmingham City University (BCU) do Reino Unido. Professor do Departamento de Cinema, Rádio e TV (CTR) da ECA/USP e do Programa de Pós-Graduação em Meios e Processos Audiovisuais (PPGMPA) da mesma instituição. E-mail: eduvicente@usp.br

${ }^{*}$ Leonardo de Marchi é Doutor em Comunicação e Cultura pela UFRJ. Bolsista de Pós-Doutorado da Fundação de Amparo à Pesquisa do Estado de São Paulo (FAPESP) na Escola de Comunicações e Artes da Universidade de São Paulo (ECA-USP). E-mail: leonardodemarchi@gmail.com
} 


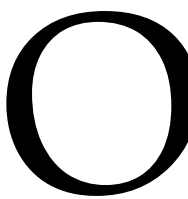

objetivo do presente artigo é apresentar um relato condensado da história da indústria fonográfica no Brasil, desde seu início, nos primeiros anos do século XX, até o atual momento de digitalização da produção, distribuição e consumo de fonogramas. Baseando-se numa pesquisa bibliográfica que compreendeu livros publicados, teses de doutorado, além das atuais pesquisas de seus autores, este trabalho pretende oferecer uma visão geral da dinâmica da indústria de registros sonoros. ${ }^{1}$ Especificamente, pretende-se apresentar uma leitura realizada desde o campo de estudos da Comunicação Social, entendendo que ela permite relacionar de forma equilibrada aspectos tecnológicos (afinal, trata-se fundamentalmente de um negócio de tecnologias da informação e da comunicação), culturais (formas de apropriação dessas tecnologias para consumo de bens culturais) assim como socioeconômicas (na medida em que se identifica uma economia política da indústria fonográfica desempenhando uma influência significativa no desenvolvimento tecnológico e no consumo cultural dos formatos fonográficos). Com isso, pretendemos lançar luz sobre relações entre esse negócio de comunicação e cultura e a música popular brasileira, auxiliando futuras pesquisas relacionadas ao tema.

O leitor irá notar que damos particular ênfase à constituição de um eixo de produção e consumo musical consolidado entre as cidades do Rio de Janeiro e São Paulo. Isso se deve a dois motivos. O primeiro é que a questão do chamado "eixo Rio-São Paulo" oferece maior relevo a um dos aspectos centrais de nossa análise, qual seja, a intensa segmentação da produção musical que se verifica no país a partir dos anos de 1990, através da atuação de um amplo leque de gravadoras e produtores independentes. O segundo vem do fato de que o termo tem surgido como uma palavra-chave nos recentes debates sobre a produção musical no país, tendo inclusive dado o nome a um movimento cultural que se autodeclara "Fora do Eixo" (uma rede de coletivos de produção cultural surgida em 2005). Dessa forma, nossa análise pretende identificar na expansão geográfica da produção musical (com a consolidação de cenas musicais importantes nas regiões norte, nordeste, centro-oeste do país) um

\footnotetext{
${ }^{1}$ Os autores agradecem à Fundação de Apoio à Pesquisa do Estado de São Paulo (FAPESP), pelo financiamento de seus respectivos projetos de pós-doutorado, que levaram à produção do presente artigo.
} 
feito cultural de grande importância para a atual dinâmica da indústria fonográfica local.

Assim, subdividimos o artigo em quatro partes, todas seguindo períodos históricos que identificamos como momentos distintos no desenvolvimento da indústria fonográfica no país. Na primeira, discutimos o surgimento do negócio fonográfico durante a primeira metade do século $X X$, desde a fundação da primeira gravadora do país, a Casa Edison, até a era do rádio, nas décadas de 1930-50. A segunda parte do texto discute o cenário das décadas de 1960 e 1970, quando se dá um grande crescimento do mercado de música popular, associado ao surgimento da mídia televisiva e à transformação da composição social da produção e do consumo de música no eixo Rio-São Paulo. Objeto da terceira parte do texto, as décadas de 1980 e 1990 serão marcadas tanto pela chegada ao mainstream de artistas oriundos do rock alternativo nos anos 1980 quanto por uma maior regionalização da produção e do consumo musical na década seguinte, momento em que o eixo Rio-São Paulo começa a perder a sua hegemonia. Esse processo de regionalização da produção musical, vinculado à emergência de uma música associada a um amplo leque de demandas identitárias, mantém-se como uma das principais características do cenário atual, aliás, objeto da quarta e última parte deste texto, que traz também nossas considerações finais.

\section{A construção de um negócio de comunicação e cultura 1900-1950}

Apesar de ser possível encontrar artigos de jornais do final do século XIX anunciando a exposição pública de fonógrafos na cidade do Rio de Janeiro, então capital do Império, deve-se considerar como sendo o início do negócio fonográfico no Brasil a década de 1900 (TINHORÃO, 1981). Conforme afirma a literatura especializada, é no ano de 1900 que ocorre a fundação da primeira loja de discos no país, a Casa Edison, que se transformaria em gravadora local, a partir de 1902, produzindo fonogramas com repertório musical local (FRANCESCHI, 2002). Para que se possa compreender as condições que permitiram o desenvolvimento de um negócio tão inovador em um país exportador de café, é necessário revisitar a própria estruturação 
da fonografia como um negócio de comunicação e cultura desde o final do século XIX

Ainda que outras tecnologias de gravação e reprodução sonoras tenham sido inventadas antes, historicamente marca-se o ano de 1878 como sendo o de criação da fonografia, quando a patente do fonógrafo é dada a Thomas Alva Edison (GITELMAN, 1999; STERNE, 2003). Apesar de ser aclamado como uma tecnologia da informação e da comunicação revolucionária, o próprio Edison encontrou grandes dificuldades para estabelecer uma maneira lucrativa para sua invenção (CHANAN, 1995; DOWD, 2002). De fato, seria apenas nos últimos anos da década de 1890 que a gravação de música se tornaria o principal conteúdo das gravações sonoras. No entanto, já a partir desse momento, a fonografia se configuraria como um negócio de alcance internacional. Ao se observarem as datas em que se dá o início da produção de fonogramas no Brasil, poder-se-ia notar que elas não são muito distintas das de outras regiões periféricas ao capitalismo industrial. Há registros do início desse negócio na Escandinávia (GRONOW, ENGLUND, 2007) e na própria América Latina (GONZÁLES e ROLLES, 2004) mais ou menos na mesma época, revelando que o desenvolvimento da indústria fonográfica em países não industrializados esteve diretamente relacionado à expansão do comércio internacional durante a chamada era dos impérios (HOBSBAWN, 1998) e a conseguinte estruturação das telecomunicações que conectavam países industrializados aos agroexportadores espalhados pelo globo.

Esses primeiros anos da fonografia foram marcados pelo uso estratégico de patentes. Através delas, regulava-se o acesso à tecnologia e se criavam monopólios de mercados ao redor do mundo. De um lado, nos países industrializados, havia empresas fonográficas que desenvolviam e controlavam a tecnologia de reprodução sonora através de patentes e que detinham plantas industriais para produção em larga escala de discos. De outro, estavam aventureiros que saíam pelas áreas coloniais em busca de localidades onde pudessem estabelecer gravadoras. Uma vez gravadas as matrizes, o material era enviado a fábricas nos países industrializados para a produção em larga escala, sendo comprado o produto manufaturado para revenda.

No Brasil, essa figura do empreendedor aventureiro foi personalizada em Frederico Figner (1866-1946). Nascido na cidade de Milevsko, então, parte do Impé- 
rio Austro-Húngaro (hoje, cidade da atual República Tcheca), ao final do século XIX, Figner emigrou para os Estados Unidos e lá iniciou uma carreira de vendedor de fonógrafos na América Latina. Excursionando com seu cunhado pelas rotas comerciais da região, chegou ao Brasil em 1891. Em 1900, instala-se definitivamente no Rio de Janeiro, então Capital Federal da recém proclamada República, onde abriu a Casa Edison, loja importadora de produtos industrializados na qual vendia diversas sortes de novidades tecnológicas, como o kinetoscópio, lanternas, telefones, máquinas de escrever, além de máquinas falantes e seus discos. O negócio de discos deve ter-lhe parecido bom, pois em 1902 deu início à gravação de fonogramas in loco, estabelecendo um estúdio de gravação em sua loja.

Para tanto, Figner celebrou um contrato com a empresa Zonophone, que se tornou depois a International Talking Machine-Odeon, ambas sediadas na Alemanha. Como Franceschi (2002, p. 88-98) detalhadamente descreve, para que se produzissem os discos exclusivamente para a Casa Edison, o empresário radicado no Brasil deveria pagar todo o processo de produção de fonogramas, desde a viagem de Berlim ao Rio de Janeiro para o técnico de gravação, até a provisão do local de gravação (estúdio) e o material técnico (discos e gramofones) e material humano (artistas e repertório ou $A \& R)$. Depois, deveria enviar as matrizes gravadas à fábrica europeia, além de ficar obrigado a comprar a maior parte dessa produção para revenda no Rio de Janeiro. Porém, a empresa alemã lhe oferecia uma contrapartida interessante: 1/3 da patente para discos duplos, que continham gravações nos dois lados dos discos, válidas para território brasileiro. Com essa inovadora tecnologia, Figner teria enorme vantagem sobre seus competidores.

Como era responsável pela seleção de A\&R, Figner não hesitou em contratar distintos músicos locais que já eram notórios na cana musical dos teatros, cinemas, cafés, gafieiras e chopes-berrantes da cidade. Assim, gravou a Banda do Corpo de Bombeiros, conduzida pelo maestro Anacleto de Medeiros, o virtuoso flautista Patápio Silva, Chiquinha Gonzaga e Ernesto Nazaré, entre outros. Também gravou diversos tipos de gêneros musicais então em voga: árias de ópera, valsas, polcas, marchas, dobrados, maxixes, lundus e xotes. Isso significa dizer que, desde logo, a 
indústria fonográfica percebia no repertório local um produto relevante para seu êxito comercial.

A partir de 1911, Figner iniciaria negociações para a construção de uma fábrica de discos na cidade. Com o suporte técnico do grupo sueco Lindström, que comprara a Odeon, importou maquinário e mandou construir uma instalação de grandes proporções. Inaugurada em 1913, a fábrica Odeon deve ser considerada a primeira fábrica de discos da América Latina. ${ }^{2}$ Ela reunia a tecnologia mais avançada à época para reprodução industrial de fonogramas, toda importada da Europa, contando ainda com 150 operários. Sua capacidade média para a produção de discos alcançava 125.000 unidades por mês, portanto, 1.500 .000 discos ao ano (FRANCHESCHI, op. cit.). Ao inaugurá-la, Figner passou a produzir discos no Brasil também para as outras empresas locais, tornando-se o principal agente de uma emergente indústria fonográfica no país.

A partir de 1927, a tecnologia elétrica de gravação sonora passaria a ser utilizada no país, permitindo aumentar a quantidade e a qualidade da produção de discos. Ao mesmo tempo, com o fim da vigência das patentes, grandes gravadoras internacionais começaram a competir por mercados periféricos através de investimentos diretos. Assim, entre 1928 e 1930, gravadoras europeias e americanas abriram filiais no país, como a Columbia, a RCA-Victor e a Brunswick, contando com o apoio de empresários locais. As vindas da Columbia e da RCA ao Brasil tiveram essa característica. No primeiro caso, a empresa se instalou por meio de uma associação com o empresário local Alberto Byington, que produzia equipamentos elétricos. Já a RCA associou-se à empresa Cássio Muniz S/ A, que responderia até 1958 pela distribuição de seus discos (VICENTE, 2014). Assim, ampliava-se a gama de competidores para a Odeon. E os novos tempos logo foram sentidos por Figner. Em 1919, face aos problemas decorrentes da Primeira Guerra Mundial, o grupo Lindström se transformou em Transoceanic Trading Company, o qual seria comprado pela Columbia Gramophone de Londres que faria parte, a partir de 1931, da Electric Musical Instruments (EMI). Já em 1926 os investidores britânicos passaram a exigir direta par-

\footnotetext{
${ }^{2} \mathrm{O}$ grupo Lindström planejava investir neste tipo de facilidade fora da Europa. Tanto que, na América do Sul, depois do Brasil, em 1913, abriu fábricas semelhantes na Argentina, em 1918, e no Chile, em 1927 (FRANCESCHI, 2002; GONZÁLES e ROLLES, 2005).
} 
ticipação na condução da filial brasileira. Aos poucos, a companhia adquiriu a posse dos catálogos da Odeon brasileira, respectivos direitos autorais das músicas gravadas e a possibilidade de administrar, do exterior, a produção de discos, inclusive no que tange à seleção musical. Em 1932, finalmente, uma nova revisão do contrato obrigaria Figner a lhes entregar a fábrica do Rio de Janeiro.

Outra inovação que transformaria decisivamente o mercado local de música nesse período seria o rádio comercial. Sua história no país é indissociável do conturbado contexto econômico e político do período. A intensificação das disputas pelo poder entre as elites que comandavam a política do país se acirraria com a crise econômica internacional de 1929, que rebaixaria o preço do café no mercado internacional. Dessa discórdia política resultaria em um golpe de Estado, a chamada Revolução de 1930, que faria de Getúlio Vargas presidente do Brasil e, pouco tempo depois, seu ditador, a partir da instauração do Estado Novo (1937-1945) (FAUSTO, 1982). O novo regime político seria decisivo para o desenvolvimento dos mercados de bens culturais do país. Por defender um tipo de nacionalismo centralizador, baseado na ideia de patriotismo, o governo de Vargas buscou criar uma comunidade imaginada, ou seja, uma "nação brasileira" onde antes havia uma fragmentação identitária que sustentava o poder das antigas elites políticas. Assim, opondo-se ao regionalismo que caracterizava o período liberal da Primeira República (1899-1930), o governo do Estado Novo buscou fazer com que a integração cultural nacional ocorresse a partir do centro do poder, a Capital Federal (Rio de Janeiro), e do culto à personalidade do grande líder (Getúlio Vargas).

Claramente inspirados nas experiências de políticas de comunicação e cultura conduzidas na Alemanha nacional-socialista e na Itália fascista, mas também na expansão do rádio pelo sistema comercial como ocorria nos Estados Unidos, os ideólogos do Estado Novo entendiam a cultura como o espaço de criação de coesão social, sendo, portanto, uma arena de disputa ideológica em que se travaria a luta contra os principais adversários do regime (o regionalismo da Primeira República e o comunismo internacionalista). Nesse sentido, os novos meios de comunicação de massa eram considerados um estratégico instrumento político, em particular o rádio. Afinal, este era um veículo que poderia ligar diretamente o líder às massas, ignorando in- 
termediários (Poder Legislativo e a opinião pública burguesa), além de prescindir da capacidade de leitura da população, um aspecto importante em um país com altos níveis de analfabetismo.

Essa preocupação levou o governo de Vargas a estatizar uma estação, a Rádio Nacional. ${ }^{3}$ Esta seria particularmente importante para o mercado de música da época. Ainda que fosse uma empresa estatal, sua programação notabilizou-se pela ênfase no entretenimento e no jornalismo (SAROLDI e MOREIRA, 2005). Tendo como objetivo se tornar a rádio mais popular do país, essa empresa apelaria para uma programação pautada em radionovelas, informes jornalísticos e também na música popular. De fato, a música popular, transmitida ao vivo ou reproduzida via discos, gozava de espaço privilegiado na programação, possuindo programas próprios, além de servir como forma de preencher as pausas entre as novelas e os noticiários ${ }^{4}$. Por isso, a emissora decidiu contratar uma grande quantidade de intérpretes e arranjadores, ou "maestros", para formar um cast exclusivo, no que foi seguida por suas concorrentes privadas.

Em seu trabalho diário, esses profissionais desempenharam um papel relevante no desenvolvimento da música popular urbana brasileira. A começar pelos chamados "maestros". Na medida em que escreviam arranjos para as músicas transmitidas ao vivo pelas emissoras de rádio, eles começaram a dar certa padronização à sonoridade da música popular. Como o êxito em uma determinada emissora de rádio facilitava a esses profissionais a entrada na indústria fonográfica, logo passaram a fazer arranjos para os discos tal como faziam nos estúdios das rádios. Sendo ao mesmo tempo compositores, arranjadores e produtores musicais de discos, maestros

\footnotetext{
${ }^{3}$ A Sociedade Civil Brasileira Rádio Nacional surgiu a partir da compra do jornal A Noite e da Rádio Phillips pela Companhia de Estrada de Ferro São Paulo-Rio Grande. Inaugurada em 18 de maio de 1933, a empresa seria incorporada ao Patrimônio da União, segundo o decreto-lei $n^{\circ} 2.073$, datando de 08 de março de 1940. O que é intrigante na Rádio Nacional é que, apesar de ser uma empresa pública, ela se organizou como uma corporação moderna, dividida em seções especializadas, dotada de um corpo administrativo profissional e até mesmo contanto com modernas técnicas de monitoramento de mercado: instituiu-se, após a intervenção estatal, uma seção de pesquisa de mercado, a fim de mensurar o desempenho da companhia em relação às suas concorrentes (SAROLDI e MOREIRA, 2005, p. 56). Isso lhe permitiu investir na contratação de técnicos de som, atores para telenovelas e músicos de uma forma talvez incomparável em relação aos seus competidores privados.

4 De acordo com dados fornecidos pela própria empresa, no ano de 1945, o percentual da programação diária dedicada à música pela estação era a seguinte: programas de música "variada" (popular, folclórica e erudita) detinham 26,9\%, os de "música popular" $11 \%$ e os de música erudita, $4,4 \%$ (SAROLDI e MOREIRA, 2005).
} 
como Pixinguinha, Radamés Gnattali, Leo Peracchi, Lyrio Panicali, entre outros, ajudaram a dar certa identidade à música popular transmitida via rádio e discos ao escolherem os mesmos repertórios, instrumentos e os intérpretes para as canções.

Não obstante o importante trabalho desses maestros e dos virtuosos músicos acompanhantes, as principais atrações da indústria da música da época eram os cantores do rádio (crooners). Graças ao desenvolvimento da tecnologia elétrica de reprodução sonora, especialmente o microfone, novos cantores puderam se destacar. ${ }^{5}$ Suas vozes pouco potentes e cheias de maneirismos somente se sobressaíam graças ao uso de microfones elétricos que conseguiam captar tais nuances e dos discos reproduzidos eletricamente, cuja capacidade de manter uma "alta fidelidade", para utilizar um termo que ganha destaque nessa época, tornava possível valorizar a maneira de cantar desses novos intérpretes. Alguns se notabilizaram pelo controle do microfone, como Carmen Miranda e Mário Reis. É interessante notar que o sucesso desses cantores não se devia apenas às suas vozes transmitidas pelo rádio como também a um conjunto de publicações especializadas em música e entretenimento (jornais e revistas) que traziam novidades da indústria da música e da vida pessoal dos cantores e cantoras, seguindo, ainda que de forma modesta, o modelo hollywoodiano do star system. Além das publicações periódicas, o emergente cinema brasileiro da década de 1930 apostou em musicais e, com isso, contratou diversos cantores para estrelarem as chamadas "chanchadas", um gênero fílmico caracterizado pelo humor burlesco (CIOCCI e CARRASCO, 2013). Com a crescente familiaridade do som e com a imagem dos cantores e o conseguinte interesse da população pela vida dos cantores, as emissoras de rádio buscaram competir através de contratos de exclusividade para seu cast com eles. É nessa época que surgiriam os primeiros "astros" (stars) da música popular brasileira, como a já citada Carmen Miranda, Francisco Alves, Aracy de Almeida, Marlene, Emilinha, Cauby Peixoto, entre outros.

Iniciava-se, assim, um círculo virtuoso que, tendo o rádio como elemento central de produção e divulgação da música popular, nutria uma incipiente indústria

\footnotetext{
${ }^{5}$ De acordo com João Máximo e Didier (1990), o sistema de gravação elétrica foi introduzido no Brasil em 1927. João Máximo e Carlos Didier afirmam que o primeiro disco produzido com o sistema elétrico de gravação no Brasil é o de Francisco Alves, gravado pela Odeon (número de catálogo 10.001), tendo de um lado a canção "Albertina" e, de outro, "Passarinho do má".
} 
de cultura sediada na capital federal. Contando com o apoio pessoal e institucional de Vargas, essa produção cultural feita no Rio de Janeiro passaria a assumir um status oficial de cultura popular "brasileira" (ou seja, "nacional"; não apenas “carioca”), hierarquizando outras produções culturais (VIANNA, 1990). Isso é decisivo para se estabelecerem as bases de um mercado nacional de bens culturais no Rio de Janeiro.

No entanto, sendo o principal centro da oposição a Vargas, em São Paulo também se desenvolvia uma produção cultural própria. Na década de 1930, o rádio comercial se consolidou na cidade, também por motivos políticos. Esse meio de comunicação foi fundamental para a mobilização da população durante o conflito armado que buscou retomar o poder após o golpe de Estado de 1930, a chamada Revolução Constitucionalista de 1932. Após o término do conflito, as emissoras da cidade de São Paulo puderam se dedicar ao jornalismo e ao entretenimento, tendo na música um produto barato e bastante apreciado (MORAES, 2000). Devido à sua força econômica, particularmente ao seu desenvolvimento industrial, São Paulo também pôde desenvolver seu próprio circuito cultural, com gravadoras, casa de espetáculo e estações de rádio próprias, ou seja, pôde desenvolver uma indústria de cultura própria que se colocava como uma alternativa à produção cultural divulgada desde o Rio de Janeiro.

Essa acirrada disputa política e simbólica entre a capital federal e o centro econômico do país teria diversas consequências. Para os fins deste artigo, basta sublinhar duas. A primeira é que a concentração de poder político assim como econômico nessas cidades fez delas dois polos de atração para os principais investidores mercados de bens simbólicos e, logo, para a mão de obra especializada de todo o país. A segunda é que a produção de cultura que se concentrava nesse emergente eixo relegou a uma posição secundária, marcada pela designação algo depreciativa de "regional", a produção cultural de outras regiões do país, como já observara Hermano Vianna (1999). Isso significa dizer que a formação do chamado "eixo Rio-São Paulo" de produção e consumo de bens culturais está para além de razões meramente econômicas, comportando um caráter político de grande importância. 


\section{A expansão da indústria fonográfica nas décadas de 1960 e 1970}

Não seria difícil comprovar que, a partir dos anos 1960, houve uma importante mudança no cenário da indústria fonográfica no Brasil. A década representou o início de um ciclo de grande crescimento do mercado de bens simbólicos do país (ORTIZ, 1989), com a produção de discos, segundo dados da Associação Brasileira dos Produtores de Discos (ABPD), passando de 5.5 milhões de unidades em 1966 para 52.6 milhões em 1979 (VICENTE, 2008, p. 101). Esse crescimento seria acompanhado pela chegada de outras gravadoras internacionais ao Brasil, agora de forma autônoma. A Philips instalou-se em 1960, a partir da aquisição da CBD (Companhia Brasileira do Disco), a WEA, braço fonográfico do grupo Warner, iniciou suas atividades em 1976 e a espanhola Ariola chegaria ao país em 1979. Ao mesmo tempo, percebendo as oportunidades nesse crescente mercado de música, grupos de comunicação nacionais passaram a investir também na área fonográfica. Assim, a Rede Globo de Televisão criaria, em 1969, a gravadora Som Livre, impulsionada pelo êxito dos Festivais da Canção, no que seria seguida por outras emissoras de TV. ${ }^{6}$ Além disso, a Abril, maior grupo editorial do país, responsável pelo lançamento de dezenas de revistas e coleções em fascículos, também inicia nesse período suas incursões pelo mercado fonográfico. ${ }^{7}$

O período também é marcado pelo crescimento da televisão que começa a assumir um papel central no cenário midiático brasileiro. Na medida em que essa nova mídia começava a receber mais dinheiro de patrocinadores, tirando-os do rádio, houve a migração de muitos dos programas e quadros técnicos e artísticos que anteriormente pertenciam ao rádio (ORTRIWANO, 1984). E isso viria a ter um grande impacto sobre o consumo musical do país. Será através da televisão que toda uma nova geração de artistas surgiria e alcançaria consagração. Programas televisivos como O Fino da Bossa, Jovem Guarda e, notadamente, os Festivais de Música Popular,

\footnotetext{
${ }^{6}$ As emissoras Tupi, Bandeirantes e Record promoviam os lançamentos de suas gravadoras GTA, Bandeirantes Discos e Seta, respectivamente (VICENTE, 2014, p.69).

${ }^{7}$ A Abril teria uma atuação mais destacada na área musical a partir dos anos 1990, através da criação da MTV brasileira e, posteriormente, da Abril Music.
} 
todos surgidos em meados da década de 1960, seriam responsáveis pela renovação e ampliação tanto dos produtores de música quanto de seus consumidores, passando a integrar a juventude do pós-guerra e, com isso, alterando de maneira fundamental a composição social do mercado de música popular gravada (NAPOLITANO, 2001). Não por acaso, surgem e se consagram via televisão e, depois, através de discos, nomes como Elis Regina, Jair Rodrigues, Edu Lobo, Roberto e Erasmo Carlos, Chico Buarque, Caetano Veloso e Gilberto Gil, entre outros. ${ }^{8}$

Essa nova geração de artistas, ligada a um público jovem, urbano e de maior nível socioeconômico, será absorvida notadamente pelas grandes gravadoras multinacionais que passam a operar no país. Esses novos artistas iriam ocupar o lugar vago das grandes estrelas tradicionais do rádio que, justamente com os artistas associados a um público formado pelas populações do meio rural e das periferias urbanas, ficariam restritas às emissoras de AM e seriam os principais contratados de gravadoras nacionais como RGE, Rozemblit, Copacabana, Continental e Chantecler. O rádio só voltaria a ter um papel mais destacado na divulgação musical a partir da segunda metade da década de 1970, quando se consolidarão no Brasil as emissoras comerciais de $\mathrm{FM}^{9}$.

Assim, teremos nesse momento não só um processo de estratificação do mercado musical, mas também uma divisão do trabalho entre as empresas fonográficas. Enquanto as gravadoras nacionais tradicionais ficariam restritas a artistas vinculados aos segmentos musicais de baixa aceitação pelas populações urbanas de melhor poder aquisitivo, as gravadoras multinacionais e os conglomerados locais de comunicação passariam a trabalhar com os artistas internacionais e com os nomes nacionais dessa nova geração. Muitos desses artistas estariam presentes, ao longo das décadas seguintes, também nas trilhas das telenovelas da Rede Globo. Essas trilhas, formadas normalmente por coletâneas de músicas nacionais e internacionais, transformarão a gravadora Som Livre numa das maiores vendedoras de discos do país (MORELLI, 1991, p. 70). Nesse sentido, podemos dizer que os anos 1960 e 1970 acabaram consolidando o eixo Rio/São Paulo como espaço de produção e consumo mu-

\footnotetext{
${ }^{8}$ A respeito da programação televisiva do período, consultar MORELLI (2011).

9 De qualquer modo, o FM também se concentrará no mesmo público visado pelas majors internacionais.
} 
sical em detrimento de uma produção anterior, que se voltava a um público mais regionalizado.

Nesse período, tivemos também um aumento do nível de organização e influência política do setor fonográfico. A Associação Brasileira dos Produtores de Disco (ABPD), que havia sido criada em 1958, passaria a atuar de forma mais efetiva, obtendo importantes concessões para as grandes gravadoras. Entre elas, destaca-se a aprovação de uma importante lei de incentivos fiscais, em 1967, que permitia às empresas descontarem do Imposto de Circulação de Mercadorias (ICM), com uma taxa de $17 \%$ do faturamento das empresas, todo o valor investido na produção de repertório local. Essa lei, que seria extinta nos anos 1990, garantiu um expressivo incentivo ao desenvolvimento tanto do mercado de música doméstica quanto do setor fonográfico como um todo (PRESTES FILHO, 2005).

O forte crescimento experimentado pelo setor nesse período também possibilitou o surgimento de empresas de menor porte, vinculadas a uma produção musical que não encontrava espaço nas grandes gravadoras do eixo Rio-São Paulo devido ao seu foco em um público mais restrito. Esse foi o caso, por exemplo, das gravadoras Festa, Elenco, Marcus Pereira e Eldorado. A Festa, criada em 1956 por Irineu Garcia, dedicou-se principalmente à gravação de poesia e de música erudita, mas foi a responsável pelo lançamento daquele que é considerado como o disco inaugural da Bossa Nova: Canções do Amor Demais, Elizete Cardoso, 1958. A Elenco, criada em 1962 por Aloysio de Oliveira, gravou alguns dos mais importantes discos da Bossa Nova. A Marcus Pereira, criada em 1967, trabalhou especialmente com música folclórica e regional, que procurava apresentar a um público urbano. Já a Eldorado, surgida em 1977, concentrava-se principalmente na música instrumental, erudita e na MPB. ${ }^{10}$

No entanto, o que poderíamos denominar de "movimento musical independente" surgiria apenas ao final dos anos 1970, com o lançamento de discos como Racional, de Tim Maia, em 1975, Feito em Casa, de Antonio Adolfo, em 1977, Boca

\footnotetext{
${ }^{10}$ Nenhuma dessas empresas, no entanto, assumiu um discurso independente ou atuou em segmentos musicais muito diferentes daqueles explorados pelas grandes gravadoras, que também produziam discos de Bossa Nova e de MPB. Além disso, todas elas, com exceção da Eldorado, encerraram suas atividades ainda durante a década de 1970.
} 
Livre, do grupo Boca Livre em 1979, e com o surgimento do Teatro Lira Paulistana, em São Paulo, em 1978 (VICENTE, 2014, p. 126). Foi a partir de Antonio Adolfo, da ação da Cooperativa dos Músicos do Rio de Janeiro (liderada por Chico Mário) e da atuação de diversos nomes ligados a esses polos, que a expressão “independente" passou a fazer parte dos discursos de artistas e das manchetes jornais, com o termo sendo utilizado como sinônimo de "qualidade artística" e "autonomia criativa", em oposição a alguma produção musical mais "massificada" e "alienada" estética e politicamente falando ${ }^{11}$ (DE MARCHI, 2007). Apesar de seu caráter "alternativo", é preciso notar que esse movimento independente se desenvolveu marcadamente no eixo Rio-São Paulo e que não sobreviveria ao difícil cenário econômico da década de 1980.

É preciso no entanto destacar que a menção a um eixo de produção e consumo no Brasil, durante o período aqui discutido, não deve ser compreendida como alguma limitação do star system musical a artistas desses dois centros. Cenas musicais de outros estados também tiveram importante repercussão no país, embora sempre incluídas dentro do gênero integrador da MPB e a partir do deslocamento dos artistas para São Paulo e, principalmente, Rio de Janeiro. Como exemplos, podemos citar o chamado boom nordestino, ainda na década de 1970 (BAHIANA, 1980), que envolveu artistas de diferentes estados daquela região do país 12 e o "Clube de Esquina", grupo de artistas do Estado de Minas Gerais que teve como sua figura mais importante o cantor e compositor Milton Nascimento.

Embora com menor visibilidade, também uma cena underground, inspirada pelo punk rock anglo-americano, começa a se articular de forma mais intensa no Brasil a partir do final dos anos 1970. Um dos pioneiros dessa cena foi Luiz Carlos Calanca que, proprietário da loja de discos Baratos Afins, localizada na Galeria do Rock, em São Paulo, criou em 1982 um selo com o mesmo nome da loja, pelo qual gravaram importantes artistas dessa cena, como Ratos de Porão, Voluntário da Pátria, Nau, As Mercenárias, Gueto, 365, Fellini, Akira S., entre outros. Acompanharam a iniciativa de Calanca selos como Ataque Frontal, WopBop,

\footnotetext{
11 Podemos citar, entre outros exemplos, "Como gravar sem restringir a criação" (O ESTADO, 07 jul. 1979), "A conciliação entre consumo e informação" (JORNAL, 25 nov. 1974); "A glória e o esgoto do mundo milionário do disco" (O GLOBO, 09 abr. 1975); etc.

12 Como Belchior e Fagner, do Estado do Ceará; Alceu Valença e Geraldo Azevedo do Estado de Pernambuco; Zé Ramalho e Elba Ramalho, do Estado da Paraíba.
} 
Woodstock e Rock Brigade, de São Paulo, além de Heavy Discos e Point Rock, do Rio e Cogumelo, de Belo Horizonte (DEZ ANOS, 02 fev. 1988; CORRENDO, abr. 1988). Na sequência, veremos que todas essas tendências da cena independente marcariam, de maneira indelével, a produção musical no país das décadas seguintes.

\section{Da "década perdida" ao renascimento da indústria 1980-1990}

Os anos 1980 foram marcados, no Brasil, pelo fim do ciclo de crescimento acelerado da economia, o chamado "milagre brasileiro", e a conseguinte estagnação da economia acompanhada de alta da inflação, contexto que lhes valeu o título de "década perdida". Também para a indústria fonográfica, esse período foi de adaptação a esse cenário negativo. Após anos experimentando um crescimento ininterrupto de seu mercado consumidor, a ponto de se tornar um dos grandes arrecadadores da indústria fonográfica internacional (BAHIANA, 1980), as gravadoras em operação no Brasil tiveram de se adequar à falta de previsibilidade da economia. A ilustração abaixo revela a inconstância do mercado fonográfico ao longo daquela década:

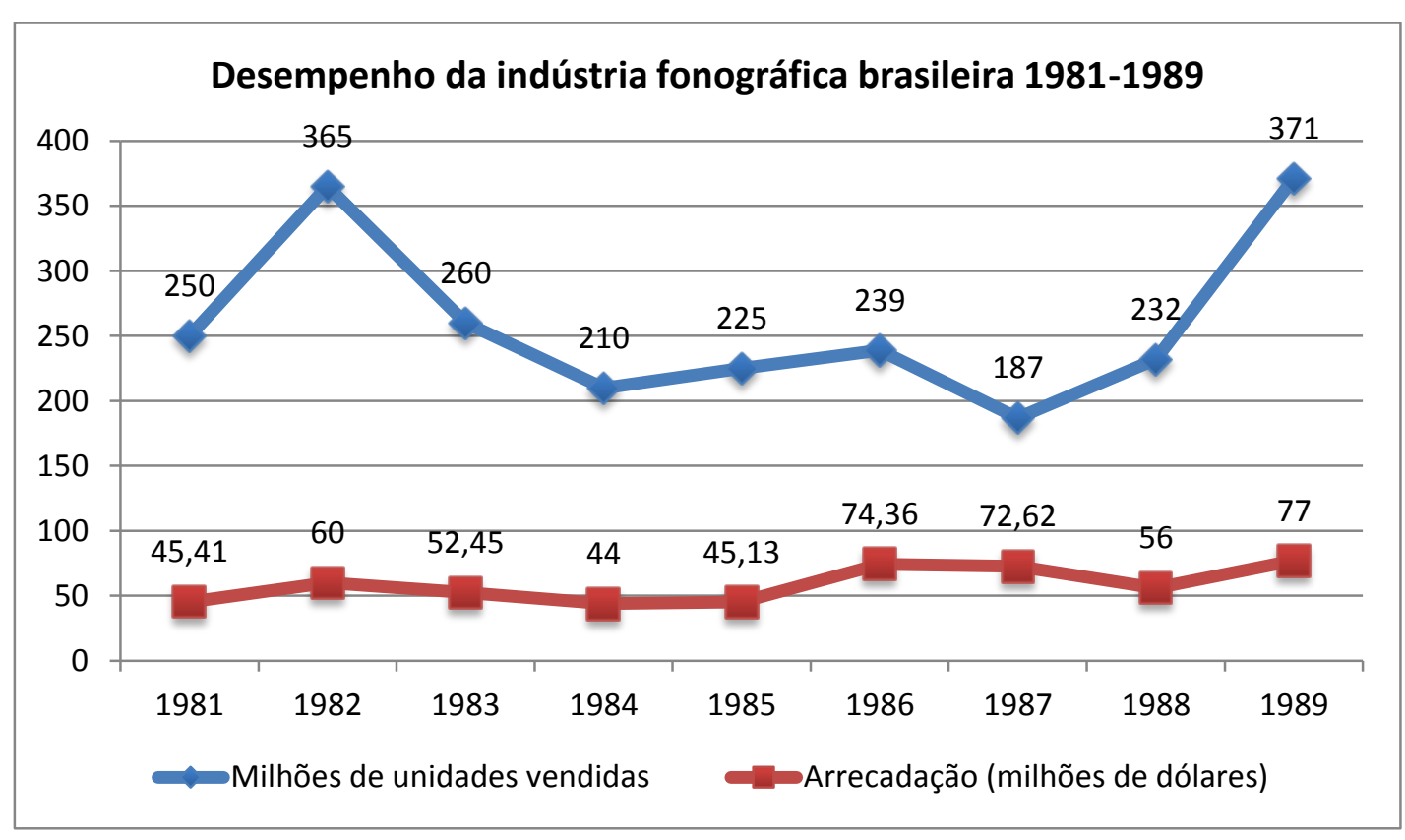

Gráfico 1 - Desempenho da indústria fonográfica brasileira entre 1981-1989 (Fonte: relatórios da ABPD apud DIAS, 2000). 
Como é possível notar, as principais gravadoras do país conseguiram manter certo equilíbrio em sua arrecadação, apesar da inconstância na venda de unidades. Isso se deve, em larga medida, à restruturação pela qual passou essa indústria no período.

Desde logo, esse cenário negativo acelerou o fenômeno de concentração do setor, uma vez que as gravadoras de capital nacional (em geral, empresas de pequeno e médio porte, ainda de caráter familiar) ou faliram ou foram adquiridas pelas grandes gravadoras multinacionais. Ao mesmo tempo, também o movimento independente arrefeceu, deixando de ser uma opção viável para novos artistas.

Mesmo as grandes gravadoras tiveram de repensar seu negócio. Assim, para otimizar seus investimentos em artistas e repertório, passaram a apostar em nichos de mercado pouco explorados até então. Um exemplo notável disso foi o segmento de música infantil. Tanto que a maior vendedora de discos do período foi Xuxa, uma apresentadora de um programa televisivo infantil da Rede Globo. Outro nicho que alcançou importância econômica para a indústria fonográfica na época foi a geração de artistas conhecida como "rock brasileiro dos anos 1980" ou Brock (DAPIEVE, 1995). Ainda que tivessem referência estéticas bastante diversas entre si, pode-se dizer que essas bandas eram uma das consequências da articulação da cena underground que se articulara no final da década anterior. Ao longo dos anos 1980, bandas como Blitz, Legião Urbana, Paralamas do Sucesso, Barão Vermelho, RPM e Titãs, entre outras, passaram a ter grande espaço nas gravadoras e desempenharam um papel importante na relativa recuperação do mercado de discos, sobremaneira na segunda parte da década. Deve-se admitir, porém, que esse nicho dava continuidade à composição social do mercado consumidor de discos no Brasil, fortemente baseado no poder de consumo das classes média e alta, uma vez que era produzida nas regiões mais desenvolvidas do país (Brasília, Rio de Janeiro, São Paulo e Porto Alegre) por artistas que eram, de um modo geral, brancos, oriundos de classe média e possuíam formação universitária.

Além do eixo Rio-São Paulo, um fenômeno inovador que começou a ganhar força na década de 1980 foi o desenvolvimento de um mercado consumidor no interior do país e nas periferias do eixo Rio-São Paulo. Com o crescente êxito do 
chamado agrobusiness, as economias do interior de estados como São Paulo, Goiás, Mato Grosso e Mato Grosso do Sul ganhavam fôlego e a composição social de sua população também se alterava significativamente. Isso lhes permitiu criar uma demanda por expressões culturais próprias, o que no caso da música esteve particularmente relacionado à transformação estética e social da tradicional música sertaneja. Se as duplas "caipiras" eram tidas mais como folclóricas ou bregas pelo mercado musical do eixo, a partir desse momento começa a se notar o surgimento de artistas profissionais que apelam mais à estética da country music norte-americana. Também a composição sociocultural de seu público se altera: já não são mais os agricultores que compõem o público consumidor dessa música emergente, mas jovens de alto poder aquisitivo oriundos do agrobusiness. Ao mesmo tempo, o crescimento dos subúrbios e periferias em grandes cidades, como Rio de Janeiro e São Paulo, fazia com que o mercado consumidor de discos não mais pudesse ser agregado baixo um denominador comum. Enquanto os remanescentes da MPB e do Brock se atinham ao público das classes média e alta das capitais, outras expressões musicais tomavam espaço entre as classes mais baixas, notadamente a black music abrasileirada (da qual derivariam o funk carioca e o RAP paulista) e a música romântica ou brega. Se é verdade que esse processo de segmentação do mercado havia se iniciado desde o final da década de 1960 (MORELLI, 2008), é a partir dos anos 1980 que ele ganha outra dinâmica (VICENTE, 2008).

Percebendo esse movimento, as grandes gravadoras do eixo passaram a se interessar mais por gêneros musicais ligados a esse público emergente. Assim, começaram a contratar artistas ligados à música sertaneja, a música romântica tradicional ou música brega, ao estilo de samba conhecido como pagode e à música baiana de carnaval, rotulada de música axé. Esse fenômeno iria se intensificar no início dos anos 1990, gerando uma série de artistas que alcançariam notável êxito comercial, como Chitãozinho e Chororó, Leandro e Leonardo, Zezé de Camargo e Luciano, Daniela Mercury, Banda Eva, o Tchan, Só para Contrariar, entre outros, cujas marcas de venda de CD (novo formato que era colocado no mercado pela indústria fonográfica no lugar dos tradicionais LP e fitas magnéticas) alcançavam cifras expressivas. $\mathrm{O}$ sucesso desses artistas, cujo público não estava restrito às classes de maior renda no 
eixo Rio-São Paulo, deveu-se a mudanças no cenário econômico do país e nas estratégias de atuação da indústria fonográfica que gostaríamos de explicitar aqui.

No cenário econômico, deve-se destacar que a implementação do Plano Real, em 1994, deu início a um período de estabilidade econômica no país depois de todos os percalços da década perdida e do início dos anos 199013. Algumas das medidas tomadas nesse processo, como a paridade entre a nova moeda, o Real, e Dólar americano, fomentou-se o consumo de bens não-duráveis. Ao mesmo tempo, também a indústria fonográfica passou por transformações de suas estruturas de produção cujas consequências provariam ser de longo alcance.

Uma das mais importantes foi a adoção da tecnologia digital como paradigma tecnológico da indústria fonográfica local. Apesar de serem comercializados nos países de economia desenvolvida desde a década anterior, no Brasil, a popularização do Compact Disc (CD) só ocorreria na década de 1990, graças a uma agressiva campanha das gravadoras para a substituição de discos em vinil (LP e compactos) e das fitas magnéticas, tipo Cassete, pelos novos discos digitais. ${ }^{14}$ Como estes eram relativamente mais caros do que seus pares analógicos, a indústria fonográfica pôde recuperar seus ganhos não apenas em unidades vendidas (os discos eram menores e mais fáceis de se estocar) como também em termos de arrecadação, como se discutirá a seguir. A tecnologia digital também seria decisiva para a terceirização de suas etapas produtivas de gravação de discos, uma vez que o equipamento para produção e reprodução de discos se padronizara por completo. Isso permitiu às grandes gravadoras delegarem as funções de gravação e produção industrial de discos a terceiros,

${ }^{13}$ A eleição do primeiro presidente da República desde o fim da ditadura não ajudou a sanar os problemas econômicos e políticos da primeira etapa da Nova República. Pelo contrário, durante a confusa gestão de Fernando Collor de Mello (1990-1992), testemunhou-se o sequestro dos ativos financeiros pelo governo, congelamento de preços e salários, início de programas de privatização de empresas estatais, abertura da economia nacional aos produtos importados e uma irrefreável corrupção na máquina estatal. Um fracasso econômico que, associado à incapacidade administrativa do novo governante, rendeu-lhe a destituição da presidência (impeachment).

14 A fim de forçar seus consumidores a migrarem rapidamente para o $C D$, as grandes gravadoras tomaram a decisão de cessar a produção de discos em vinil e de fitas magnéticas cassetes. Se em 1987 um CD equivalia a dois LP, em 1991, a relação invertera-se de dois para um (DIAS, 2001, p. 107). Segundo os dados apresentados na pesquisa coordenada por Prestes Filho (2005, p. 49), no ano de 1991, a indústria fonográfica brasileira faturou US\$28,4 milhões com a venda de Long Plays enquanto a cota de CD foi de apenas US $\$ 7,5$ milhões. Com a política de redução de custos da nova tecnologia e de substituição de formatos, entretanto, em 1994 essa diferença passaria para US\$ 14,5 milhões referentes ao vinil e US\$ 40,2 milhões ao disco digital. Em 1997, o LP pararia de ser produzido pelas grandes gravadoras e as fitas magnéticas experimentariam uma queda significativa em seu comércio. 
controlando o mercado através da distribuição dos produtos físicos e da divulgação dos artistas na mídia nacional. Essa prática não apenas diminuía os custos de produção dos CD, uma vez que o investimento era dividido entre diversos atores, como também prometia otimizar o marketing dos artistas, pois as empresas independentes teriam mais condições de explorar essa maior diversidade musical, normalmente vinculada a demandas identitárias locais dos mais diversos tipos. Para levar isso a cabo, houve a popularização de equipamentos digitais de produção musical, o que levou à proliferação de estúdios de gravação em todas as regiões do país. Nesse momento, rompia-se o monopólio de gravação sonora das gravadoras presentes no eixo Rio-São Paulo.

Esse cenário de fragmentação da produção fonográfica acarretou o ressurgimento e a consolidação de gravadoras independentes de capital nacional, como Trama, Biscoito Fino, Deck Disc, Indie Records e Atração Fonográfica, entre outras, que passam a desempenhar um papel relevante na descoberta de novos artistas e até mesmo na continuidade da carreira de nomes consagrados, como Chico Buarque, Milton Nascimento, Rita Lee e Maria Bethânia. Essa reorganização do setor independente, depois de décadas de predomínio quase absoluto das majors multinacionais, ficaria marcada pela criação da Associação Brasileira da Música Independente (ABMI), em São Paulo, no ano de 2001, que chegou a reunir dezenas de selos independentes e que visava, assim como a ABPD no passado, constituir-se como um agente político de defesa dos interesses do setor (DE MARCHI, 2006; VICENTE, 2006).

Essa produção descentralizada de discos garantiu uma nova onda de crescimento de vendas para a indústria fonográfica local. De acordo com os dados divulgados pela ABPD, entre 1990 e 1999, houve um crescimento 114,38\% em vendas de unidades físicas, tendo o ano de 1998 como o ápice desse movimento (107,9 milhões de unidades vendidas). Esse crescimento foi tão expressivo que, em 1996, as gravadoras filiadas à ABPD arrecadaram juntas cerca de 1.394,5 milhões de dólares americanos, passando a ocupar o $6^{\circ}$ lugar no ranking mundial da Federação Internacional da Indústria Fonográfica (IFPI, 1999; YÚDICE, 2007). 
Além disso, o consumo de música popular também passava por importantes mudanças. Cada vez mais, a música que era gravada passava a ter uma maior vinculação identitária regional. Isso podia ser notado na cena de rock underground. Como se observou anteriormente, essa cena havia surgido nos anos 1970 e alcançado o mainstream musical, no decênio seguinte, com uma música fortemente ligada a um público de classe média, de importantes centros urbanos do Sul e Sudeste do país. Nos anos 1990, no entanto, deu-se uma renovação estética e social a partir do sucesso de bandas relacionadas a identidades negras, oriundas das periferias desses grandes centros urbanos e influenciadas pelo funk e por outros gêneros da black music. Esse foi o caso de bandas como O Rappa, Planet Hemp, Pedro Luís e a Parede e Cidade Negra, entre muitas outras. Além disso, regiões distantes do eixo Rio-São Paulo tornaram-se importantes centros de produção musical. Caso notório é Recife, onde surgiu o Movimento Manguebeat, um movimento musical da periferia da cidade que deu visibilidade a dezenas de bandas, com destaque para Chico Science \& Nação Zumbi e Mundo Livre S/A, que misturavam influências da black music, do rock e do pop internacionais, com referências da MPB e da música regional, como o maracatu e o cavalo-marinho. Além disso, a cidade também abrigou um dos mais importantes festivais de música independente, o Festival Abril pro Rock, responsável pela revelação de novos nomes no cenário nacional, como Los Hermanos.

Também no cenário da black music nacional tivemos importantes modificações. Se nos anos 1970 e 1980 os primeiros artistas vinculados a uma black music brasileira, fortemente inspirada pelo soul e pelo funk norte-americano, como Tim Maia, Hyldon, Sandra Sá e Cassiano, foram, de certa forma, "acomodados" sob o guarda-chuva da MPB, a partir dos anos 1990, a cena adquiria maior autonomia, diversidade e se tornaria mais regionalizada. O funk carioca ganhava projeção nacional tanto através do Funk Melódico quanto do "Funk Batidão" (Miami Bass), de forte apelo sexual. O hip hop de São Paulo se destacava a partir de grupos como o Racionais MC's, chegando a ser o grande vencedor do Video Music Brasil (VMB) da 
MTV brasileira de $1998^{15}$. Na Bahia, grupos musicais vinculados a projetos sociais como Olodum e Timbalada, entre outros, marcavam o que foi definido por alguns autores como a "reafricanização da Bahia". São Luís do Maranhão tornava-se conhecida, por sua vez, como a capital brasileira do reggae e celebrava a sua proximidade com o Caribe.

Ao final da década de 1990, portanto, a indústria fonográfica brasileira vivia seu ápice econômico e, talvez, seu momento de maior diversidade cultural entre seus produtos. Ao contrário do que ocorrera na década de 1970, desta vez, esse círculo virtuoso estava ancorado na atomização da produção e, portanto, na exploração de nichos musicais. Porém, essa diversidade da produção ainda se encontrava fortemente dependente das decisões das grandes gravadoras instaladas no eixo Rio-São Paulo. Afinal, eram elas que controlavam os principais sistemas de distribuição de discos físicos para as diferentes regiões do país e mantinham um estreito laço com os meios de comunicação de massa de alcance nacional. Não obstante, as condições estavam postas para uma nova fase de reestruturação desse negócio, a qual viria com o advento das redes digitais de comunicação.

\section{A construção de um mercado digital de fonogramas 2000-2010}

A partir do ano de 1999, inicia-se uma diminuição da venda de discos assim como da arrecadação das principais gravadoras do país que se mostraria persistente nos anos seguintes. Se em 1999 a Associação Brasileira de Produtores de Discos (ABPD) registrara a venda de 88 milhões de unidades de discos físicos, após dez anos, esse número havia passado para apenas 25,7 milhões. Isso teve um reflexo direto na arrecadação das gravadoras associadas à instituição: nesse mesmo período, a redução foi da ordem de 72,66\% (DE MARCHI, 2011).

Sem compreender o que ocorria, uma vez que em outras oportunidades em que suas vendas haviam diminuído se estava em meio a alguma "crise" da economia nacional, os principais agentes da indústria fonográfica acusaram o que rotu-

\footnotetext{
${ }^{15} \mathrm{O}$ grupo obteve os prêmios de melhor clipe de rap e Clipe do Ano pela votação popular por “Diário de um Detento" (que falava do massacre de 111 prisioneiros no presidio do Carandiru, em São Paulo), além de realizar um aclamado show durante o evento, cf. VIDEO, 1998.
} 
lavam de "pirataria" como a causa de sua própria "crise". Esta categoria nativa se dividia entre "pirataria física" (contrafação de CD e DVD) e "pirataria digital" (compartilhamento gratuito de arquivos digitais pela internet). Assim, em seu relatório anual referente ao ano de 2002, a ABPD afirmava que desde que o CD foi adotado como suporte da indústria de contrafação (1997), o comércio de discos pirateados passou a representar de 3\% para 59\% do total do mercado brasileiro de discos físicos (ABPD, 2003). Já em seu relatório referente ao ano de 2005 (ABPD, 2006), a entidade divulgou uma das poucas pesquisas sobre as práticas de consumo de fonogramas por redes digitais no Brasil. Nesse documento, estimava-se que em 2004 cerca de um bilhão de arquivos havia sido baixado sem autorização dos detentores dos direitos autorais das obras e que cerca de três milhões de pessoas baixavam com frequência arquivos de música no Brasil via P2P, blogs ou páginas de internet. Além disso, 4,2\% das pessoas pesquisadas afirmaram que gravavam em CD-R os arquivos que baixavam pela internet. De acordo com a lógica da instituição, se tais arquivos baixados fossem comprados na forma de $C D$, estes teriam rendido às gravadoras o equivalente a dois bilhões de Reais naquele ano fiscal: três vezes mais do que então havia sido obtido pelas gravadoras associadas.

Ainda que plausível, a centralidade que o argumento da pirataria assumia deixava certa suspeita de que ele era, na melhor das hipóteses, insuficiente para explicar o que se passava no mercado fonográfico brasileiro. Por mais que tanto a contrafação de discos físicos quanto o compartilhamento de arquivos pela internet de fato retirassem consumidores do mercado formal16, a ABPD ignorava outras causas que evidentemente exerciam alguma influência naquela drástica mudança de cená-

16 É preciso observar que os números apresentados pela indústria fonográfica brasileira são questionáveis. No caso da contrafação de discos físicos, as enormes somas de dinheiro que os agentes da indústria fonográfica apresentavam baseavam-se no número de apreensões de discos gravados pela Polícia Federal. Assim, contabilizava-se cada disco digital "pirata" apreendido por um comprado em lojas autorizadas. No entanto, não havia certeza da relação de substituição entre um disco oficial e outro "pirata". O mesmo consumidor que comprou três discos falsificados, por exemplo, poderia não comprar essa mesma quantidade de discos se só lhe fosse dada a possibilidade de fazê-lo em pontos de venda autorizados. Já no caso do compartilhamento de arquivos digitais, a metodologia era ainda mais problemática: tomava-se cada arquivo digital pelo preço de uma faixa que compõe um disco e, então, calculava-se o suposto montante de dinheiro que não ingressava para as gravadoras, artistas e editoras. Outra vez, nada poderia garantir que um consumidor compraria a mesma quantidade de arquivos digitais que baixava gratuitamente. Até mesmo porque muitas vezes se baixam diversos arquivos a fim de se conseguir apenas uma ou duas canções. 
rio. Notadamente, os representantes de gravadoras e editoras de música insistiam em não admitir as profundas transformações na organização e no funcionamento de seu próprio negócio. Entre esses diversos fenômenos, gostaríamos de destacar três.

1) A radicalização da produção fonográfica descentralizada: se ao longo dos anos 1990, as tecnologias digitais permitiram o surgimento de uma rede de prestadores de serviços e de pequenas e médias gravadoras nacionais, o desenvolvimento da indústria de microinformática facilitou o acesso de indivíduos a equipamento eletrônicos de gravação e reprodução sonoras (homestudios, samplers digitais, sintetizadores digitais etc.), permitindo que os próprios músicos começassem a gravar suas obras, prescindindo de qualquer auxílio de gravadoras.

Isso foi decisivo para remodelar a indústria da música no país. Desde logo, facilitou que os próprios artistas conduzissem suas carreiras de forma autônoma, criando verdadeiras bandas-empresas, ou seja, bandas que se tornaram pessoas jurídicas a fim de que pudessem realizar concertos e vender seus produtos sem a necessidade de intermediários (gravadoras ou empresas de concertos ao vivo) (DE MARCHI, 2012). Passando às margens do mainstream musical, alguns desses empreendimentos conseguiram obter notoriedade em todo o país e relativo êxito comercial. Exemplos notórios são: O Teatro Mágico (São Paulo), Móveis Coloniais de Acaju (Brasília-DF), Forfun (Rio de Janeiro), Calcinha Preta (Aracaju) e os Aviões do Forró (Fortaleza).

2) Sistemas alternativos de distribuição de fonogramas: a enorme produção resultante dessa descentralização radicalizada teria necessariamente de ser escoada por vias alternativas àquelas dominadas pelas grandes gravadoras do eixo RioSão Paulo. Estas se materializaram em inusitados pontos de venda de discos, como concertos ao vivo, templos religiosos, bancas de jornal, entre outros lugares em que os artistas e seu público frequentavam em comum, prescindindo de grandes mediadores (HERSCHMANN, 2010). Além disso, é importante notar que essa produção também era realizada com alternativas para os CD e DVD. Merece destaque, nesse sentido, o uso de tecnologias mais baratas de reprodução sonora, como o Semi Metalic 
Disc ou SMD ${ }^{17}$. Somados, esses fatores diminuíam o custo dos discos digitais para os consumidores, acarretando graves consequências para a estabelecida indústria de discos. Afinal, tais inovações (a) colocavam em questão a legitimidade das lojas de disco como instituição representante da indústria fonográfica, (b) diminuíam o preço do produto final para os consumidores, aumentando as possibilidades de escolha (CD, DVD e SMD) e, com isso, (c) retiravam o poder das gravadoras de controlar o fluxo de produtos no mercado através de seus sistemas de distribuição.

3) O mercado de fonogramas digitais: entre tais vias alternativas de distribuição estão, é claro, as redes digitais de comunicação. Enquanto as instituições representantes da indústria fonográfica insistiam em criminalizar os usuários de programas P2P e paralisavam seus investimentos no mercado digital, os artistas autônomos passaram a explorar as possibilidades comerciais que as redes digitais ofereciam. Assim, bandas como o Teatro Mágico ou o Móveis Coloniais de Acaju desenvolveram todo um sistema de comunicação virtual com seus fãs, oferecendo de maneira gratuita seus fonogramas a fim de ampliar sua base de consumidores. Essa ação visava dois objetivos, basicamente. Por um lado, fazia com que os próprios fãs que se cadastravam em seus blogs, websites e perfis de redes sociais na internet (notadamente o Orkut e o Facebook) se tornassem os principais divulgadores de suas obras (que não tocavam nas rádios tradicionais). Por outro, eram oferecidos a esses fãs diversos outros produtos (camisetas, ingressos para concertos e até mesmo edições especiais de seus CD e DVD), que buscavam compensar a doação dos fonogramas digitais.

Entre a inoperância das gravadoras e a experimentação dos artistas autônomos, empreendedores locais da indústria de Tecnologias da Informação (TI) ofereceram as primeiras empresas eletrônicas de música. Prometendo gerir o fluxo de fonogramas pelas redes digitais, essas empresas buscaram se tornar os novos intermediários da indústria fonográfica na era digital (DE MARCHI, ALBORNOZ, HERSCHMANN, 2011). Mesmo encontrando certa dificuldade para se consolidarem entre os agentes da indústria fonográfica, esses empreendedores começaram a de-

17 O Semi Metalic Disc (SMD) resulta de uma nova técnica de gravação das informações em discos digitais que reduz o preço de comercialização de um CD em cerca de $80 \%$ de seu custo total. 
senvolver um efetivo mercado digital no país, que seria uma base para a entrada de agentes internacionais na década seguinte.

Essa entrada de importantes empresas eletrônicas de música no cenário internacional se dá a partir de dois eventos: a assinatura do acordo entre Youtube e o Escritório Nacional de Arrecadação e Distribuição de direitos autorais (ECAD) e o início da iTunes Store Brasil. Ainda que funcionasse no país desde 2007, apenas em 2010 o Youtube entrou em acordo com o ECAD, estabelecendo uma fórmula para que o site pudesse realizar o pagamento pelos vídeos protegidos por direitos autorais no Brasil. Em 2011, foi a vez da Apple negociar com as editoras e gravadoras para poder abrir uma versão de sua loja virtual no país. Esses acordos permitiram estabelecer, em primeiro lugar, uma forma simplificada de pagamento dos direitos autorais sobre o conteúdo de música digital no país, facilitando o diálogo entre os detentores desses direitos (artistas, editoras e gravadoras) e empresas eletrônicas. Em segundo, atraíram para o Brasil outras empresas estrangeiras, criando uma rede própria de prestadores de serviços para o mercado digital. Não por acaso, em seguida, passaram a operar no país serviços de streaming, como a francesa Deezer, a americana Rdio e a anglo-sueca Spotify, além de agregadores de conteúdos digitais como a americana The Orchard e a inglesa Believe Digital, as duas principais empresas no ramo. Isso trouxe confiança aos tradicionais agentes da indústria fonográfica local que passaram a investir no mercado digital. De acordo com os dados da ABPD referentes ao ano de 2012 (ABPD, 2013), as empresas eletrônicas de música que enviaram dados à associação tiveram um crescimento de 83,1\% em relação ao ano fiscal anterior, arrecadando 111.435.842,00 de Reais (cerca de 47.437.675,19 de Dólares).

A entrada dessas empresas confirma que, também no Brasil, as redes digitais de comunicação se tornaram o principal mercado para a indústria fonográfica no século XXI. Há muitos aspectos ainda a serem resolvidos, é verdade, como a questão dos direitos autorais, ou ainda, a velocidade e a qualidade da internet no país. Não obstante, não há dúvidas de que existe toda uma nova constelação de agentes que se interpõe às relações comerciais mantidas entre os tradicionais agentes (músicos, empresários culturais, gravadoras, meios de comunicação de massa, editoras, consumidores), criando assim outro negócio. Finalmente, pode-se afirmar que a transição da 
fonografia de um negócio industrial de discos físicos para um de venda de serviços de conteúdos digitais já está em andamento no país.

\section{Considerações finais}

Ao longo deste artigo, buscamos desenvolver uma história da indústria fonográfica no Brasil, cobrindo um período que se estende desde a década de 1900 até a de 2010. Em nossa narrativa, privilegiamos o fator geográfico, por entender que ele seria decisivo para se compreender a gravidade das atuais transformações pelas quais passa a indústria da música no país. Assim, articulamos fenômenos políticos, econômicos, sociais e culturais que fizeram do eixo Rio de Janeiro e São Paulo o epicentro de uma indústria cultural brasileira assim como sublinhamos as principais razões que permitiram que, nas últimas décadas, houvesse uma descentralização da produção musical. Fenômenos como o movimento Fora do Eixo, o tecnobrega do Pará, o funk carioca, o RAP paulista, as bandas-empresas como Móveis Coloniais de Acaju ou O Teatro Mágico, ou ainda, as novas práticas de consumo de música pelas redes digitais de comunicação somente podem ser compreendidas como grandes inovações no cenário cultural do país ao se levar em conta esse contexto histórico.

Afinal, sua importância reside em que eles refazem diversas fronteiras: entre o eixo Rio-São Paulo e o restante do país, entre o mainstream musical e suas margens, entre a comunicação de massa e a comunicação digital em rede. Em seu conjunto, a crescente importância que assumem essas diferentes experiências de produção musical faz com que as fronteiras entre o mainstream musical e suas margens se estreitem (HERSCHMANN, 2011), criando novas possibilidades de negócios com música gravada que se colocam como alternativas viáveis à tradicional produção e venda de discos em alguns poucos revendedores autorizados. Sua importância é de tal ordem que permite aos agentes que formam essa indústria questionarem a legitimidade de suas tradicionais instituições (lojas de discos, as gravadoras, os discos físicos, a ABPD, a legislação de direitos autorais, entre outras), abrindo um novo horizonte de possibilidades tanto estéticas quanto comerciais. 
Finalmente, gostaríamos de sublinhar que o panorama histórico que aqui buscamos oferecer está longe de esgotar o tema. Pelo contrário, há inúmeros assuntos que merecem atenção dos pesquisadores. Nosso objetivo foi apresentá-lo de forma coerente, a fim de que sejam explorados detalhadamente no futuro. Enfim, esperamos ter dado subsídios para pesquisas futuras e apontado uma bibliografia especializada para pesquisadores interessados na indústria da música no Brasil.

\section{Referências bibliográficas}

ASSOCIAÇÃO BRASILEIRA DE PRODUTORES DE DISCOS. Mercado brasileiro de música 2002. Rio de Janeiro: ABPD, 2003. Disponível em:

<http:/ / www.abpd.org.br/downloads.asp>. Acesso em: 01 dez. 2003.

. Mercado brasileiro de música 2005. Rio de Janeiro: ABPD, 2006. Disponível em: <http://www.abpd.org.br/downloads.asp>. Acesso em: 15 ago. 2006.

. Mercado brasileiro de música 2012. Rio de Janeiro: ABPD, 2013. Disponível em: <http://www.abpd.org.br/ downloads.asp>. Acesso em: 10 jul. 2013.

BAHIANA, Ana Maria. Importação e Assimilação: rock, soul, discotheque. In: NOVAES, Adauto (org.). Anos 70: Música Popular. Rio de Janeiro: Ed. Europa, 1980, p. 41-51

BORIS, Fausto. A revolução de 1930. 8. ed. São Paulo: Brasiliense,1982.

FRANCESCHI, Humberto M. A Casa Edison e seu tempo. Rio de Janeiro: Sarapuí, 2002.

CHANAN, Michael. Repeated takes: a short history of recording and its effects on music. London \& New York: Verso, 1995

CIOCCI, Sandra; CARRASCO, Ney. Os cantores do rádio que protagonizaram filmes da Atlântida. Música Popular em Revista, Campinas, ano 2, v. 1, p. 74-98, jul.-dez. 2013.

CORRENDO por fora. Revista Bizz, ano 4, n. 4, abr. 1988.

DAPIEVE, Arthur. Brock: o rock brasileiro dos anos 80. 2a ed. São Paulo: Ed. 34, 1995.

DE MARCHI, Leonardo. Indústria Fonográfica e a Nova Produção Independente: o Futuro da Música Brasileira? Comunicação, Mídia e Consumo, São Paulo, v. 03, p. 167182, 2006. 
O significado político da produção fonográfica independente brasileira. ECompós, Brasília, v. 1, p. 2-21, 2007.

. Transformações estruturais da indústria fonográfica no Brasil 1999-2009:

Desestruturação do mercado de discos, novas mediações do comércio de fonogramas digitais e consequências para a diversidade cultural no mercado de música. Tese.

(Doutorado em Comunicação e Cultura) - ECO/UFRJ, Rio de Janeiro, 2011.

; ALBORNOZ, Luis A.; HERSCHMANN, Micael. Novos negócios

fonográficos no Brasil e a intermediação do mercado digital de música. Revista FAMECOS, v. 18, p. 279-291, 2011.

. Inovação e institucionalização na indústria fonográfica brasileira: um estudo de caso das estratégias de negócio de músicos autônomos no entorno digital. Revista EPTIC, v. 14, p. 1-22, 2012.

DEZ ANOS de ousadia. Jornal da Tarde, 02 fev. 1988.

DIAS, Márcia T. Os donos da voz: indústria fonográfica brasileira e mundialização da cultura. São Paulo: Boitempo, 2000.

DOWD, Timothy J. Culture and commodification: technology and structural power in the early U.S. recording industry. The International Journal of Sociology and Social Policy, n. 22, p. 106-140, 2002.

GITELMAN, Lisa. Scripts, grooves and writing machines: representing technology in the Edison era. Standford: Standford University Press, 1999.

GONZÁLES, Juan P.; ROLLE, Claudio. História social de la música popular en Chile 1890-1950. Santiago: Ediciónes Universidad Pontifícia Católica de Chile: Casa de las Américas, 2004.

GRONOW, Pekka; ENGLUND, Björn. Inventing recorded music: the recorded repertoire in Scandinavia 1899-1925. Popular Music, Reino Unido, vol. 26, n. 02, p. 281-304, 2007.

HERSCHMANN, Micael. Indústria da música em transição. São Paulo: Estação das Letras e Cores, 2010.

. Nas bordas e fora do mainstream musical: tendências da música independente no início do século XXI. São Paulo: Estação das Letras e Cores, 2011.

HOBSBAWN, Eric. A era dos impérios 1875-1914. 11. ed. Rio de Janeiro: Paz e Terra, 1998. 
INTERNATIONAL FEDERATION OF THE PHONOGRAPHIC INDUSTRY. The Recording Industry in Numbers 99: the definitive source of global music market information. Londres: IFPI, 1999.

JORNAL do Brasil. Rio de Janeiro, 25 nov. 1974

MÁXIMO, João; DIDIER, Carlos. Noel Rosa: uma biografia. Brasília: Ed. UnB, 1990.

MIDANI, André. Música, ídolos e poder: do vinil ao download. Rio de Janeiro: Nova Fronteira, 2008.

MORAES, José G. V. Metrópole em sinfonia: história, cultura e música popular na São Paulo dos anos 1930. São Paulo: Estação Liberdade, 2000.

MORELLI, Rita C. L. O campo da MPB e o mercado moderno de música no Brasil: do nacional-popular à segmentação contemporânea. ArtCultura, Uberlândia, v. 10, n. 16, p. 87-101, jan.-jun. 2008.

2009.

. Indústria fonográfica: um estudo antropológico. 2. ed. Campinas: Ed. Unicamp,

Música na TV de São Paulo nas décadas de 1950 e 1960: investimentos identitários e estatutários, XV CONGRESSO BRASILEIRO DE SOCIOLOGIA, julho de 2011, Curitiba (PR). Disponível em:

$<$ http://portal.anpocs.org/portal/index.php?option=com_docman\&task=doc_view \&gid=2247\&Itemid=229>. Acesso em: 28 dez. 2014.

NAPOLITANO, Marcos. Seguindo a canção: engajamento político e indústria cultural na MPB 1959-1969. São Paulo: Annablume, 2001.

O ESTADO de São Paulo. São Paulo, 07 jul. 1979.

O GLOBO. Rio de Janeiro, 09 abr. 1975.

ORTIZ, Renato. A moderna tradição brasileira: cultura brasileira e indústria cultural. 5. ed. São Paulo: Brasiliense, 1994.

ORTRIWANO, Gisela S. A informação no rádio: os grupos de poder e a determinação dos conteúdos. São Paulo: Summos, 1984.

PRESTES FILHO, Luís C. (coord.). Cadeia produtiva da economia da música. Rio de Janeiro: Instituto Gênesis/ PUC-RJ, 2005.

SAROLDI, Luiz C.; MOREIRA, Sonia, V. Rádio Nacional: o Brasil em sintonia. 3. ed. Rio de Janeiro: Jorge Zahar Editor, 2005. 
STERNE, Jonathan. The audible past: cultural origins of sound reproduction. Durham \& London: Duke University Press, 2003.

TINHORÃO, José R. Música popular: do gramofone ao rádio. São Paulo: Ática, 1981.

VIANNA, Hermano. O mistério do samba. Rio de Janeiro: Zahar, 1999.

VICENTE, Eduardo. A vez dos independentes(?): um olhar sobre a produção musical independente do país. e-compós. Revista da Associação Nacional de Pós-Graduação em Comunicações, 2006.

. Segmentação e consumo: a produção fonográfica brasileira 1965-1999.

ArtCultura, Uberlândia, v.10, n. 16, p. 103-121, jan.- jun. 2008.

. Da Vitrola ao iPod: uma história da indústria fonográfica no Brasil. São Paulo:

Alameda Editorial, 2014.

VIDEO Music Brasil (VMB) 1998. Museu dos eventos - Anhembi Parque. 1998.

Disponível em: <http:/ / mueap.com.br/site/eventos-ver.php?t=1\&a=98\&c=907>.

Acesso em: 24 dez. 2014.

YÚDICE, George. La transformación y diversificación de la indústria de la música. In: Anais del seminario internacional para la coperación cultura-comunicación em iberoamérica. Madrid: Fundación Alternativas, 2007. p. 1-13.

ZAN, José R. A Gravadora Elenco e a bossa nova. Cadernos da Pós-Graduação, Campinas, IA/Unicamp, vol. 2, n. 1, p. 64-70, 1998. 